\title{
Research on Patent Information Service in University Libraries Oriented to Whole Scientific Research Process: Practices from China
}

\author{
Ya-Ping WU \\ Library, Huazhong University of Science and Technology, Wuhan, 430074, China \\ 1823052058@qq.com
}

Keywords: Patent information service, Whole scientific research process, University library.

\begin{abstract}
Patent information service has become an important part of the scientific research of university library, which is closely connected with scientific and technological innovation activities. Patent information service also is an important route of library service innovation. The research on the patent information embedded in the whole scientific research process has become a hot research topic. Oriented to the whole scientific research process, the patent information service content in university libraries is analyzed and some suggestions for carrying out the patent information service effectively are put forward at the same time.
\end{abstract}

\section{Introduction}

University is the key part of national innovation system of science and technology and its researchers have strong demand for patent information service. Based on the literature information resource, university library has various database resources, a large number of professionals in library information and science, good facilities and technical means. Thereby, university library has the ability to carry out patent information services. On December 13, 2016, State Intellectual Property Office of The P.R.C issued Rules of Intellectual Property Management for higher education institutions which explicitly defines university library as the supportive IP service organization and specifies the corresponding responsibilities [1]. University libraries are required to provide service support for the establishment, implementation and operation of intellectual property management system. In this situation, many university libraries take patent information service as one of the important directions of service transformation. Patent information service in the library has become a hot research topic in recent years. In practice, current patent information services of university library mainly focus on traditional services such as patent novelty searching, reader training, patent retrieval, etc [2]. Meanwhile, some qualified universities have provided in-depth patent information analysis services, such as technical development trend analysis, technical competition situation analysis, patent evaluation, etc [3,4]. Along with the advancement of China's innovation strategy, the scientific research environment of the university has undergone profound changes. Over the next few years, patent information service of the university library will be significantly developed in areas of service objects, service contents, and service modes. The practice of patent information service will enter a rapid development period. [2]. The current patent information service provided by the university library is far from meeting the demands of customers. Therefore, creative service modes and safeguards measures are required to satisfy the increasing customer demands.

\section{Background of Developing Patent Information Service in the University Library}

As the literature information center, the university library is equipped with rich document information resources and analysis tools as well as professional information service teams, while servicing the teaching and research development is its prime function. Under the time background of innovation and entrepreneurship, the implementation of patent service from the university library is significant. 


\section{IP Strategy is an Important Part of National Innovation and Development Strategy}

China's National Long- and Medium-Term Scientific and Technological Development Plan (20062020) is proposed to comprehensively promote the national innovation system with Chinese characteristics. Under the guidance of the Plan, China aims to, by 2020, transform into an innovation-oriented country and enter the top tier of the innovative economy leading the world. Among the various element of the national innovation system, IP strategy has increasingly become the core factor to promote international competitiveness and the crucial support to establish the innovation-oriented country. In December 2007, the implementation of IP strategy was brought up at the 17th CPC National Congress. In June 2008, the State Council promulgated the Outline of National Intellectual Property Strategy elevating IPR to national critical strategy in a full implementation phase.

\section{Institution of Higher Education is an Important Subject of National Innovation System}

Universities and colleges are major bases for cultivating talents, producing and disseminating new knowledge and new ideas, and play a significant role in the national scientific and technological innovation system. In the construction of national sci-tech innovation system, the government has boosted the support in scientific research and personnel training in universities from system-level, and further promoted enthusiasm of teachers and students in sci-tech innovation, which continuously enhances the innovation capability. Universities and colleges are becoming the cradle of high-level personnel training, the base of sci-tech innovation, the source to foster the new industry, the essential support to the national and local economy, and the main force in China's scitech innovation.

\section{Patent Information Service is an Important Link of Service Innovation of Library}

With the development of network and information technology, massive collection of information resources is become more easily. In this background, the daily business in university libraries have been greatly affected, and gradually transited from collecting, preserving and sharing information resource into digging, analyzing and utilizing knowledge. The general librarians are requested to be subject intelligence experts and information analysts to provide professional services. As a result, the library is turned from the data storage institution into the important organization of knowledge management and service. Patent information integrating technology, legislation, and economy information, holds significant value in sci-tech innovation, marketing competition, and strategic decision-making. The development of patent service in the university library is a good opportunity to implement the transformation of the library, and it is also an important information service guarantee for the development of university scientific research.

\section{The Content of Patent Information Service in University Library Oriented to Whole Scientific Research Process}

The scientific and technological innovation activities of colleges and universities are a round-robin process, which according to the chronological order activities, can be divided into three main phases: the phase of scientific innovation proposal, the $R \& D$ phase and the phase of outcome acceptance and application. In the different phases, the rules and characteristics of scientific research and demanding patent information are not the same. Based on the distinct demands and features of these three different phases, this paper put forward the content of patent information services for the Whole Process of Scientific Research.

\section{Patent Information Service in the Phase of Scientific Innovation Proposal}

University sci-tech innovation team, especially the patented technology R\&D personnel must first analyze and study the patent documentation in the relevant field at the proposal stage of scientific research, and insight into the development of the technology frontier to improve the origin of technological innovation. At the stage of project selection and project proposal about scientific innovation, libraries are able to launch patent information quality education, patent retrieval service, 
and patent novelty searching service. (1) Patent information literacy education is mainly patent publicity and patent training. Patent documents integrating technology, law, and economy information, is an extensive information resource containing a huge amount of data. The function of patent documents in scientific innovation is more outstanding than the other literature. According to US Patent and Trademark Office, 95\% inventions are recorded in patent documents and $80 \%$ are recorded exclusively. As one of the important part in the national innovation system, universities and colleges can fully explore the value of patent documentation so as to promote the scientific innovation and innovative application. The patent information literacy education of university can be implemented in various forms, e.g., brochures, seminars, online courses, elective courses relating to patent documentation search. These approaches aim to strengthen researcher's awareness of intellectual property and improve their capability of patent documentation search and utilization. (2) Patent information search is the foundation of the application of patent documentation. Generally, based on the user's requirements, the search targets include patent technology information, patent family, patent legal status, patent citation, and patent-related person. (3) Patent search can support users in a research project to understand whether the technical concept has been patented by others, before the R\&D stage. Alternatively, before applying for the patent, the patent search can assist users to determine the newness of the technical solution in order to estimate the feasibility of patent application. Prior to the decision making of product manufacture and selling, the patent search can help manufacturer's products to avoid falling into the scope of protection of other patent rights.

\section{Patent Information Service in the R\&D Phase}

In the process of $R \& D$ of research projects, the library need to provide the basic information service, e.g., patent analysis of institutions, analysis of technology development direction, and competition analysis, etc. (1) For specific institutions, the patent analysis of institutions is the analysis of patent filing trends, technology composition, and patent filing areal distribution. The analysis can assist users to understand the situation of main applicants in industry, as well as the technical composition and areal distribution of patent filings from different applicants. Additionally, the analysis can support users to discover the cooperation relation between applicants, the applicants who have the predominance in a specific field, and the role of a particular applicant in the life cycle of a specific technology. (2) The analysis of technology development direction utilized the information of patent filing trends, patent applicants, inventors, technical effectiveness, patent IPC classification, and areal distribution of inventors in a certain industry. It analyzes the development laws of industrial technology, the overall technology development and global distribution, to locate the current hotspots of technology, and determine the critical technology in industrial development and life cycles of each technology branch. (3) Patent documentation is the preferred source of competitive intelligence. By the analysis of similar patent applicants, the competitor can be discovered, meanwhile, identifying whether the competitor is a technology-type competitor (research institutions or higher education institutions) or a product-type competitor (manufacturers with massive production capability). Studies and analysis of a technology-type competitor's patented technology fields, patent filing areal distribution and the legal status offer users to understand the strategic purpose of the competitor, assess the strength of opponents, even seek the best $R \& D$ partner among many opponents.

\section{Patent Information Service in the Scientific Application Phase}

In the phases of acceptance and accomplishment of scientific research projects as well as the follow-up stage of achievement management and application, the library can vigorously expand high-level patent intelligence service, e.g., the patent database customization, patent value assessment, and patent results management. (1) Patent database customization can help users fully understand the competitive environment, mitigate the patent litigation risk with the reference to the existing technology, and develop competition strategy. In general, the user, firstly determines the scope of data source and query mode in the specialized database, secondly confirms the development plan of the management software, thirdly constructs the special patent database (including the abstract and the full-text information) which enables the user to carry out the industry 
analysis, the product or the technical analysis and the competitor analysis. (2) Patent value assessment is commonly based on the technical, legal and commercial aspects. With the reference to the same type of other patents, the comprehensive evaluation of the patent is analyzed based on various aspects including its technical value, market value, and legal value. The patent value evaluation of university research team mainly focuses on technical value. (3) The primary work of patent outcome management includes achievements appraisal, registration, declaration, reward, result confidentiality and transformation of results, etc. Libraries can provide supportive services to the technical outcome management institution in the university. These services can be collecting the statistics about patent filing in the whole university over the years and then conducting assessment and analysis, proposing a suggestion report on the classification management, regularly providing latest statistical analysis of patent results in the university, submitting the annual sci-tech achievement permit/transfer/pricing/investment to administrative department, promoting the research cooperation and the transformation from sci-tech outcomes to achievements and rewards, fully utilizing the patent mining technology to protect the potential innovation achievements which assists the layout of peripheral patents relating to core patents.

\section{Strategy and Suggestion}

In order to effectively implement the patent information service oriented to the whole scientific research process, we must build the service team for patent information, establish the database of featured patent information, and pay attention to the cultivation of patent information service personnel.

\section{Building the Service Team for Patent Information}

To implement the library patent information service, we must have a strong organizational guarantee and optimize the original library structure to establish a more flexible, flat organizational structure. This paper proposes a strategy to build a patent information service team based on the establishment of patent information service specialists in the university library.

First of all, it is suggested to set up a full-time position of patent information service in the university library, on basis of which to establish the patent information service department to provide patent informative support for the university's IP management committee and operational institutions. Its responsibilities include daily patent retrieval, patent novelty search and analysis, patent training, patent information resource platform construction. In addition, service teams need to be created to provide the whole process of IP information services for scientific research projects. Thirdly, in the school-related management agencies, various faculties and research team, IP specialists should be set-up as well.

Service team building is the core content of the IP service support organization. In the purpose of providing embedded patent information services in the whole process of research projects, many jobs, e.g., patent retrieval, patent novelty search and analysis, early warning, tracking, etc. are required to be completed, which is a extremely challenging task demanding the service specialist for knowledge and capability and relying on a wide range of personnel to form a team to develop the service. For each key research project, the library should build the service team of patent information service specialists drawn from departments of patent information service, information consulting, information technology, digital resource. The team has to integrate into the large scientific research team, thereby library service team, IP specialists from university research management team and IP specialists from research team can jointly implement patent information service. This will facilitate library patent information service specialists, scientific research personnel, and scientific research management departments to maintain effective communication, information exchange, coordination, and cooperation as well as to keep abreast of the needs of users and provide personalized, multi-level, all-around patent information service. 


\section{Establishing the Characteristic Patent Information Resource Repository}

University library patent information service is inseparable from the support of information technology relying on a strong infrastructure and software analysis tools. The infrastructure includes high-performance servers, large storage devices, and service terminals while the software mainly consists of two technologies. (1) Patent information mining and analysis tools: the patent analysis software provided by commercial organizations, e.g., Innography, Thomson Innovation, Thomson Data Analyzer, etc. The software has powerful data mining capabilities to exploit the global patent data from multi-angle, in the meantime, they can panoramically analyze and visualize the patent data, e.g, patent statistical analysis, patent strength analysis, and patent early warning analysis. The library is supposed to purchase appropriate software based on the needs of information analysis. Qualified colleges can utilize big data analysis approach and develop targeted analysis tools. (2) The patent information service platform is a comprehensive platform integrating patent information resources navigation, patent information network search and analysis tools, patent knowledge dissemination, and patent intelligence display. On this platform, users can retrieve patent information in China and abroad, familiarize patent information service contents, consult patent services related issues, achieve patent knowledge sharing, etc. Thereby, the university library is supposed to be committed to building this technology platform.

\section{Paying Attention to the Cultivation of Patent Information Service Talents}

Without a qualified patent information service personnel, it is impossible to complete a top level of patent information service. In addition to master the general library and information professional knowledge about database search approaches and analysis tools, staffs must also have the knowledge associated with the patent to provide patent information service. First, the theoretical basis of patent analysis needs to be studied to have a general understanding and in-depth thinking about the relevant concepts and technologies. Second, correct patent analysis methods should be mastered including quantitative and qualitative analysis methods to be able to use patent analysis tools, to implement a profound of statistical analysis and explain the results from the technical and economic point of view. Third, the patent-related laws and regulations need to be familiarized in order to provide analysis corresponding to patent termination, patent validity, patent licensing and other legal issues. Additionally, it is necessary to understand the relevant disciplines and related technical fields. To provide users with the whole process of scientific research patent information services specialists, staffs must be integrated into the service team and research group, actively communicating with users. Furthermore, staffs must deeply study the background of the research project as well as the target, contents, and requirements to comprehensively and timely understand the user's patent information service demands features and scope so as to provide targeted services. Consequently, librarians are required to have good communication and cooperation skills.

However, the number of professional librarians with the capabilities listed above is too few to build a team and have a scale effect, which seriously hinders the development of patent information service in the university library. Therefore, China's university libraries have to reasonably allocate human resources and strengthen the training of patent information service personnel. One way is to fully excavate the potential of existing librarians and select experienced librarians with professional library information service knowledge to build the team of patent information service. Afterward, the team members can be trained by many ways such as providing them with the specialized training of patent information services, encouraging them to participate in relevant meetings, strengthening exchanges with other librarians in university libraries, and sharing excellent practices and cases, etc. Besides, it is supposed to promote specialists with professional knowledge of discipline from each faculties and research teams, enhance their abilities related to patent information, IP management, database search methods, analysis tools, and etc., and cultivate them into patent information service specialists to contribute to the whole process of scientific research patent information service. In this way, the team consisting of librarians and specialists from various departments can be built to co-develop patent information service and promote IP transformation and technological innovation. 


\section{References}

[1]State Intellectual Property Office. GB/T 33251-2016 Intellectual Property Management Standards in Universities[S]. Beijing: Standards Press of China, 2016

[2]Shen Jinhua, Zhang Gengping. Studies on Patent Information Service of Academic Library[J].Journal of Academic Library,2016(6):51-55

[3]Wang Liping, Yang Bo, Qin Xia, et al. The Contents, Models and Trends of Patent Information Service in University Libraries[J]. Library and Information Service,2015,59(6):113-119

[4]Li Feng. Exploration and Practice of Patent Information Service in University Libraries[J]. Library Development, 2016(7): 78-81 